\title{
The Relationship Between Self-Esteem and Sexual Self-Concept in People With Physical-Motor Disabilities
}

\author{
Mehrdad Salehi ${ }^{1}$; Hooman Kharaz Tavakol ${ }^{1}$; Maede Shabani ${ }^{1}$; Tayebe Ziaei ${ }^{2, *}$ \\ ${ }^{1}$ Department of Psychiatry, Isfahan University of Medical Sciences, Isfahan, IR Iran \\ ${ }^{2}$ Counseling and Reproductive Health Research Centre, Golestan University of Medical Sciences, Gorgan, IR Iran \\ ${ }^{*}$ Corresponding Author: Tayebe Ziaei, Counseling and Reproductive Health Research Centre, Golestan University of Medical Sciences, Gorgan, IR Iran. Tel: +98-9111758007, Fax: +98- \\ 1732425171, E-mail: tayebe.ziaee@yahoo.com
}

Received: November 15, 2014; Revised: December 3, 2014; Accepted: December 15, 2014

\begin{abstract}
Background: Self-esteem is the value that the individuals give themselves, and sexual self-concept is also a part of individuality or sexualself. Impairment or disability exists not only in the physical body of disabled people but also in their attitudes. Negative attitudes affect the mental health of disabled people, causing them to have lower self-esteem.

Objectives: This study aimed to examine the relationship between self-esteem and sexual self-concept in people with physical-motor disabilities.

Patients and Methods: This cross-sectional study was conducted on 200 random samples with physical-motor disabilities covered by Isfahan Welfare Organization in 2013. Data collection instruments were the Persian Eysenck self-esteem questionnaire, and five domains (sexual anxiety, sexual self-efficacy, sexual self-esteem, sexual fear and sexual depression) of the Persian multidimensional sexual selfconcept questionnaire. Because of incomplete filling of the questionnaires, the data of 183 people were analyzed by the SPSS 16.0 software. Data were analyzed using the t-test, Man-Whitney and Kruskal-Wallis tests and Spearman correlation coefficient.

Results: The mean age was $36.88 \pm 8.94$ years for women and $37.80 \pm 10.13$ for men. The mean scores of self-esteem among women and men were $15.80 \pm 3.08$ and $16.2 \pm 2.90$, respectively and there was no statistically significance difference. Comparison of the mean scores of sexual anxiety, sexual self-efficacy, sexual self-esteem, sexual fear and sexual depression among men and women showed that women scored higher than men in all domains. This difference was statistically significant in other domains except the sexual self-esteem (14.92 \pm 3.61 vs. $13.56 \pm 4.52)(\mathrm{P}<0.05)$. The Kruskal-Wallis test showed that except for sexual anxiety and sexual self-esteem, there was a statistical difference between other domains of people's sexual self-concept and degree of disability $(\mathrm{P}<0.05)$. Moreover, Spearman coefficient showed that there was only a correlation between men's sexual anxiety, sexual self-esteem and sexual self-efficacy with their self-esteem. This correlation was positive in sexual anxiety and negative in two other domains.

Conclusions: Lack of difference in self-esteem of disabled people in different degrees of disability and in both men and women suggests that disabled people should not be presumed to have low self-esteem, and their different aspects of life should be attended to, just like others. Furthermore, studies should be designed and implemented based on psychological, social and environmental factors that can help disabled people to promote their positive sexual self-concept through marriage, and reduce their negative self-concept.
\end{abstract}

Keywords:Self-Esteem; Physically Disabled; Sexual Self-Concept

\section{Background}

According to the World Health Organization (WHO), disability is a set of physical or mental impairments that deprive the individual of independent personal and social life (1). Almost everyone experiences temporary or permanent disability at some point of life (2). According to the 2011 census, there are 1,100,000 disabled people in Iran (3). In the comprehensive guide to disability right laws, a disabled person is someone who, according to medical commission of the Welfare Organization, suffers physical, mental, psychological or combined damage with ongoing and substantial impairment in his general health and function, and reduction in his social and economic independence. Based on this guide, disabilities are categorized into 6 major and common groups including physical-motor, mental, visual, and hearing, speech and psychiatry (1). People with physical disabilities often are less educated and are socially isolated; the negative attitudes and psychosocial barriers affect their mental health (4). Some studies have shown the reduced selfesteem and self-confidence and impaired interpersonal and social communication in disabled people (5). Self-esteem is a set of feedbacks and beliefs that people express in their relations with the outside world indicating how much people consider themselves powerful, valuable and important. Self-esteem is the fourth need in Maslow's hierarchy of needs (6) and is a personal experience whose manifestation can be observed in meaningful words and behaviors (7-9).

Heydari et al. showed the difference of self-esteem between disabled and normal students. They also found that life satisfaction is lower in physically disabled people than in normal people (10). Sexual issues are one of

Copyright (C) 2015, Iranian Red Crescent Medical Journal. This is an open-access article distributed under the terms of the Creative Commons Attribution-NonCommercial 4.0 International License (http://creativecommons.org/licenses/by-nc/4.0/) which permits copy and redistribute the material just in noncommercial usages, provided the original work is properly cited. 
the important needs in a person that affect his life satisfaction. Sexual health is a physical, emotional, mental and social health related to sexual issues. In other words, sexual health is not only the lack of sexually transmitted infections and sexual dysfunction; it also encompasses emotions, behavior and control of thoughts (11). The individual's perception of his sexual desires and sexual orientation is sexual self-concept (12). In general, self-concept is a multidimensional factor evaluating the individual's psychological function and includes his thoughts and perception of himself (13). Sexual self-concept is derived from past experiences and appears in the current experiences, affects the process of social information related to sexuality and directs sexual behaviors (14). Thus, selfesteem and self-efficacy may affect general health and sexual self-concept may influence sexual behavior health. Given that promotion of health and quality of life for disabled people is one of the WHO's objectives, in this paper addressing an objective of a larger study (thesis of MD degree with No. 393014), the relationship between selfesteem and sexual self-concept was examined in people with physical-motor disabilities.

\section{Objectives}

This study aimed to determine the relationship between self-esteem and sexual self-concept status in people with physical-motor disabilities in terms of gender and the degree of disability.

\section{Patients and Methods}

\subsection{Study Population and Sampling}

This cross-sectional study was conducted on 200 people with physical-motor disabilities (congenital or non-congenital) covered by Isfahan Welfare Organization in 2013. This organization is a governmental state, which support (social, economic and educational support and so on) people with disabilities (all type of disabilities, mental and physical). Isfahan is located on the main north-south and east-west routes crossing Iran, and was once one of the largest cities in the world. Inclusion criteria included age over 18 years old, consent to participate, not having mental retardation, absence of severe anxiety and mood disorders, severe personality disorders and psychotic disorders that prevent answering properly. Unwillingness to participate was the exclusion criteria. After obtaining permission, the file numbers of people with physicalmotor disabilities, those who covered by Isfahan Welfare Organization and had inclusion criteria, were written on one list. After name selection using a table of random numbers, the necessary explanations were transmitted to the subjects on the phone, and upon agreement, they were invited to room participate in this study. Two of the researchers met them at their home. Upon agreement, they were asked to read, sign on an informed consent sheet; then they received the questionnaires and filled them out. In this study, according to the International Classification of Functioning, Disability and Health (ICF), which is also applied in Welfare Organization, disability of people was classified into four categories of mild, moderate, severe and very severe (15).

\subsection{Sample Size}

Among study population, 200 subjects were selected using the simple random sampling. The sample size, considering confidence level $=95 \%$, test power $=80 \%, \mathrm{SD}=5(16)$, was considered 200 people (100 women and 100 men).

$n=\frac{\left(Z_{1-\frac{\alpha}{2}}+Z_{1-\beta}\right)^{2}(\mathrm{~S})^{2}}{d^{2}}=\frac{(1.96+0.84)^{2}(5)^{2}}{1^{2}}=196 \simeq 200$

\subsection{Instruments}

Data were collected using the Eysenck self-esteem questionnaire (in Persian), and five domains (sexual anxiety, sexual self-efficacy, sexual self-esteem, sexual fear and sexual depression) of the Persian multidimensional sexual self-concept questionnaire. The Eysenck (17) inventory has 30 two-option items scored 0 and 1, and measures people's self-esteem. The inventory's total scores show the selfesteem score. The score of $\leq 15$ show low self-esteem and scores $>15$ show high self-esteem. The validity and reliability of the Persian version were confirmed in different studies with Cronbach's alpha 0.88 and 0.87 (17-20).

The multidimensional sexual self- concept questionnaire is an objective self-report instrument that measures different domains of psychology in the sexual field and its validity and reliability were determined by Ziaei et al. (16) In this questionnaire, the answers are scored based on Likert scale from zero (it is not true about me at all) to 4 (it is completely true about me). In their study, Cronbach's alpha was reported 0.88 for the reliability of sexual anxiety (items 1, 6, 11,16, 20), 0.85 for sexual self-efficacy (items 2, 7,12,17,21), 0.72 for sexual self-esteem (items $3,8,13,18), 0.76$ for sexual fear $(4,9,14,17,21)$ and 0.76 for sexual depression $(5,10,15,20)$.

\subsection{Ethical Considerations}

Ethical issues including plagiarism, informed consent, misconduct, data fabrication and/or falsification, double publication and/or submission, and redundancy were completely observed and considered by the authors. The Ethics Committee of Isfahan University of Medical Sciences approved the thesis (code No. 393014; date: 2013).

\subsection{Statistical Analysis}

From a total of 200 questionnaires, only 183 were fully completed, so all statistical analyses and findings are related to 183 subjects. Lack of normality which test by Kolmogorov-Smirnov, conducted the authors to use nonpara- 
Salehi Met al.

metric tests to analyze the data (21). To compare self-esteem and dimensions of sexual self-concept in both sexes, the Mann-Whitney test was used and the degree of disability was also analyzed by the Kruskal-Wallis test. The relationship between self-esteem and dimensions of sexual selfconcept scores was determined by the Spearman correlation coefficient. All tests were performed in SPSS version 16 .

\section{Results}

The results showed that $51.4 \%$ of the subjects were women and $48.6 \%$ were men. The mean age of the subjects was $32.37 \pm 9.52$ years $(36.88 \pm 8.94$ for women and $37.80 \pm 10.13$ for men). Most subjects were single (51.4\%), high school graduates (37.7\%), unemployed (50.3\%) and classified as severe in terms of degree of disability (47.5\%)(Table 1). The mean score of self-esteem in women was $15.80 \pm 3.08$ and in men $16.02 \pm 2.90$, with no significant difference. Also, there was no significant difference between individuals' self-esteem and their degree of disability (Table 2).

Comparison of mean scores of sexual self-concept; sexual anxiety, sexual self-efficacy, sexual self-esteem, sexual fear and sexual depression in women and men revealed that women scored higher than men in all domains. In all domains except for sexual self-esteem (14.92 \pm 3.61 vs. $13.56 \pm 4.52)$ a significant difference was seen between both sexes $(\mathrm{P}<0.05)$ (Table 2 ). Results showed a positive correlation between positive dimensions of sexual selfconcept and also a positive correlation between negative dimensions of sexual self-concept. However, there was a negative correlation between positive and negative sexual self-concept in both women and men (Table 3 ).

Data analysis showed that except for sexual anxiety and sexual self-esteem, there was a significant difference between the obtained mean scores and degree of disability in other domains $(\mathrm{P}<0.05)$, so that the highest mean score of sexual self-efficacy related to the mild degree of disability and the lowest to disability with severe degree $(16.35 \pm 3.31$ vs. $11.10 \pm 4.30)(P=0.047)$, the highest mean score of sexual fear related to the moderate degree of disability and the lowest to disability with severe degree $(7.39 \pm 5.03$ vs. $5.18 \pm 4.02)(\mathrm{P}=0.034)$ and the highest mean score of sexual depression related to very severe degree of disability and the lowest to disability with severe degree $(4.10 \pm 2.02$ vs. $2.45 \pm 3.21)(P=0.032)$ (Table 4$)$.

Findings showed a positive correlation between subjects' self-esteem and sexual anxiety and a negative correlation between their self-esteem and sexual self-efficacy and sexual self-esteem. There was no significant relationship between self-esteem and sexual fear and sexual depression (Table 5). Correlation analysis of self-esteem and sexual self-concept according to gender was significant only for men (Table 6). Finally, findings showed a negative correlation between self-esteem and sexual self-efficacy $(\mathrm{R}=-0.33, \mathrm{P}=0.002)$ and sexual self-esteem $(\mathrm{R}=-0.26, \mathrm{P}=$ $0.01)$ in severe degree of disability, and only between selfesteem and sexual self-efficacy $(r=-0.76, P=0.01)$ in the very severe degree of disability (Table 7$)$.

\begin{tabular}{|c|c|c|}
\hline Variables & Value & Total \\
\hline Gender & & $183(100)$ \\
\hline Female & $94(51.4)$ & \\
\hline Male & $89(48.6)$ & \\
\hline \multicolumn{3}{|l|}{ Marital status } \\
\hline Single & & $94(51.4)$ \\
\hline Female & $60(63.8)$ & \\
\hline Male & $34(38.2)$ & \\
\hline Married & & $89(48.6)$ \\
\hline Female & $34(36.2)$ & \\
\hline Male & $55(61.8)$ & \\
\hline \multicolumn{3}{|l|}{ Job } \\
\hline Unemployed & & $92(50.3)$ \\
\hline Female & $45(47.9)$ & \\
\hline Male & $47(52.8)$ & \\
\hline Clerk & & $25(13.7)$ \\
\hline Female & $18(19.1)$ & \\
\hline Male & $7(7.9)$ & \\
\hline Teacher & & $1(0.5)$ \\
\hline Female & $1(1.1)$ & \\
\hline Male & 0 & \\
\hline Other & & $60(32.8)$ \\
\hline Female & $26(27.7)$ & \\
\hline Male & $34(38.2)$ & \\
\hline \multicolumn{3}{|l|}{ Education level } \\
\hline Illiterate & & $7(3.8)$ \\
\hline Female & 0 & \\
\hline Male & $7(7.9)$ & \\
\hline Read and write & & $22(12)$ \\
\hline Female & $13(13.8)$ & \\
\hline Male & $9(10.1)$ & \\
\hline EleMaletary & & $40(21.9)$ \\
\hline Female & $15(16)$ & \\
\hline Male & $25(28.1)$ & \\
\hline Diploma & & $69(37.7)$ \\
\hline Female & $34(36.2)$ & \\
\hline Male & $35(39.3)$ & \\
\hline $\begin{array}{l}\text { Student at the } \\
\text { university }\end{array}$ & & $8(4.4)$ \\
\hline Female & $5(5.3)$ & \\
\hline Male & $3(3.4)$ & \\
\hline Bachelor & & $35(19.1)$ \\
\hline Female & $26(27.7)$ & \\
\hline Male & $9(10.1)$ & \\
\hline Upper grade & & $1(0.5)$ \\
\hline Female & $1(1.1)$ & \\
\hline Male & 0 & \\
\hline \multicolumn{3}{|l|}{ Disability degree } \\
\hline Mild & & $14(7.7)$ \\
\hline Female & $12(12.8)$ & \\
\hline Male & $2(2.2)$ & \\
\hline Moderate & & $68(37.2)$ \\
\hline Female & $35(37.2)$ & \\
\hline Male & $33(37.1)$ & \\
\hline Severe & & $87(47.5)$ \\
\hline Female & $39(41.5)$ & \\
\hline Male & $48(53.9)$ & \\
\hline Very severe & & $10(5.5)$ \\
\hline Female & $5(5.3)$ & \\
\hline Male & $5(5.6)$ & \\
\hline
\end{tabular}


Salehi Metal.

\begin{tabular}{|c|c|c|c|c|c|}
\hline Variables & Women & Men & Total & $\mathbf{Z}$ & PValue \\
\hline Self-esteem & $15.80 \pm 3.08$ & $16.02 \pm 2.90$ & $15.91 \pm 2.98$ & -0.89 & 0.37 \\
\hline \multicolumn{6}{|c|}{$\begin{array}{l}\text { Dimensions of Sexual } \\
\text { self-concept }\end{array}$} \\
\hline Sexual anxiety & $12.14 \pm 3.05$ & $11.21 \pm 4$ & $11.69 \pm 3.56$ & -2.39 & 0.016 \\
\hline Sexual self-efficacy & $5.78 \pm 4.44$ & $4.46 \pm 4.85$ & $5.14 \pm 4.67$ & -1.99 & 0.046 \\
\hline Sexual self-esteem & $14.92 \pm 3.61$ & $13.56 \pm 4.52$ & $14.26 \pm 4.12$ & -1.30 & 0.191 \\
\hline Sexual fear & $7.26 \pm 4.30$ & $5.28 \pm 4.65$ & $6.30 \pm 4.57$ & -2.95 & 0.003 \\
\hline Sexual depression & $3.43 \pm 3.40$ & $2.47 \pm 2.90$ & $2.96 \pm 3.20$ & -2.11 & 0.035 \\
\hline
\end{tabular}

${ }^{\mathrm{a}}$ Data are presented as Mean $\pm \mathrm{SD}$.

Table 3. Correlation Among the Dimensions of Sexual Self-Concept

\begin{tabular}{|c|c|c|c|c|c|c|c|c|c|c|}
\hline & \multicolumn{2}{|c|}{ Sexual Anxiety } & \multicolumn{2}{|c|}{ Sexual Self-Efficacy } & \multicolumn{2}{|c|}{ Sexual Self-Esteem } & \multicolumn{2}{|c|}{ Sexual Fear } & \multicolumn{2}{|c|}{ Sexual Depression } \\
\hline & $\mathbf{R}$ & PValue & $\mathbf{R}$ & PValue & $\mathbf{R}$ & P Value & $\mathbf{R}$ & P Value & $\mathbf{R}$ & PValue \\
\hline \multicolumn{11}{|c|}{ Sexual anxiety } \\
\hline Women & 1 & & $-0.24^{a}$ & 0.019 & $-0.35^{b}$ & 0.000 & $0.59^{b}$ & 0.000 & $0.73^{b}$ & 0.000 \\
\hline Men & 1 & & $-0.49^{b}$ & 0.000 & $-0.49^{b}$ & 0.000 & $0.70^{b}$ & 0.000 & $0.68^{b}$ & 0.000 \\
\hline \multicolumn{11}{|c|}{$\begin{array}{l}\text { Sexual self- } \\
\text { efficacy }\end{array}$} \\
\hline Women & & & 1 & & $0.77^{b}$ & 0.000 & $-0.38^{b}$ & 0.000 & $-0.25^{a}$ & 0.015 \\
\hline Men & & & 1 & & $0.76^{b}$ & 0.000 & $-0.50^{b}$ & 0.000 & $-0.62^{b}$ & 0.000 \\
\hline \multicolumn{11}{|c|}{$\begin{array}{l}\text { Sexual self- } \\
\text { esteem }\end{array}$} \\
\hline Women & & & & & 1 & & $-0.39^{b}$ & 0.000 & $-0.21^{\mathrm{a}}$ & 0.036 \\
\hline Men & & & & & 1 & & $-0.56^{b}$ & 0.000 & $-0.64^{b}$ & 0.000 \\
\hline \multicolumn{11}{|c|}{ Sexual fear } \\
\hline Women & & & & & & & 1 & & $0.54^{b}$ & 0.000 \\
\hline Men & & & & & & & 1 & & $0.63^{b}$ & 0.000 \\
\hline \multicolumn{11}{|c|}{$\begin{array}{l}\text { Sexual depres- } \\
\text { sion }\end{array}$} \\
\hline Women & & & & & & & & & 1 & \\
\hline Men & & & & & & & & & 1 & \\
\hline
\end{tabular}

Table 4. Mean of Self-Esteem and Dimensions of Sexual Self-Concept Regarding the Degrees of Disability ${ }^{a}$

\begin{tabular}{lccccc}
\hline Variables & Mild & Moderate & Severe & Very Severe & P Value \\
\hline Self-esteem & $14.92 \pm 1.94$ & $15.61 \pm 2.77$ & $16.29 \pm 3.16$ & $16.30 \pm 3.88$ & 0.322 \\
$\begin{array}{l}\text { Dimensions of } \\
\text { sexual self-concept }\end{array}$ & & & & \\
\hline Sexual anxiety & $6.21 \pm 5.27$ & $5.01 \pm 4.84$ & $4.96 \pm 4.47$ & $4.50 \pm 4.74$ & 0.833 \\
Sexual self-efficacy & $16.35 \pm 3.31$ & $14.16 \pm 4.15$ & $14.40 \pm 4.09$ & $11.10 \pm 4.30$ & 0.047 \\
\hline Sexual self-esteem & $12.21 \pm 3.26$ & $11.22 \pm 3.89$ & $12.14 \pm 3.10$ & $10.83 \pm 5.29$ & 0.528 \\
Sexual fear & $7.14 \pm 4.65$ & $7.39 \pm 5.03$ & $5.18 \pm 4.02$ & $5.80 \pm 4.23$ & 0.034 \\
\hline Sexual depression & $4.07 \pm 3.12$ & $3.07 \pm 3.28$ & $2.45 \pm 3.21$ & $4.10 \pm 2.02$ & 0.032 \\
\hline
\end{tabular}

\footnotetext{
${ }^{a}$ Data are presented as mean $\pm S D$.
} 
Table 5. Correlation Between Self-Esteem and Dimensions of Sexual Self-Concept

\begin{tabular}{lcc}
\hline Variable & \multicolumn{2}{c}{ Self-Esteem } \\
\cline { 2 - 3 } & $\mathbf{R}$ & P Value \\
\hline Sexual anxiety & $0.21^{\mathrm{a}}$ & 0.004 \\
Sexual self-efficacy & $-0.28^{\mathrm{a}}$ & 0.000 \\
Sexual self-esteem & $-0.23^{\mathrm{a}}$ & 0.001 \\
Sexual fear & 0.018 & 0.808 \\
Sexual depression & 0.051 & 0.493 \\
\hline a Correlation is significant at the 0.01 level (2-tailed).
\end{tabular}

Table 6. Correlation between Self-Esteem and Dimensions of Sexual Self-Concept in Both Sexes

\begin{tabular}{lcc}
\hline & \multicolumn{2}{c}{ Self-Esteem } \\
\cline { 2 - 3 } & R & P Value \\
\hline Sexual anxiety & 0.19 & 0.54 \\
Women & $0.23^{\mathrm{a}}$ & 0.028 \\
\hline Men & & \\
Sexual self-efficacy & -0.02 & 0.801 \\
\hline Women & -0.50 & $0.000^{\mathrm{b}}$ \\
\hline Men & & \\
\hline Sexual self-esteem & -0.13 & 0.205 \\
\hline Women & -0.32 & $0.002^{\mathrm{b}}$ \\
\hline Men & & 0.621 \\
\hline Sexual fear & -0.05 & 0.256 \\
\hline Women & 0.12 & 0.774 \\
\hline Men & & \\
\hline Sexual depression & -0.03 & \\
\hline Women & 0.16 & \\
\hline Men & & \\
\hline a Correlation is significant at the 0.05 level (2-tailed). \\
b Correlation is significant at the 0.01 level (2-tailed). \\
\hline
\end{tabular}

Table 7. Correlation Between Self-Esteem and Dimensions of Sexual Self-Concept Regarding the Different Degrees of Disability

\begin{tabular}{|lcc}
\hline Variable & \multicolumn{2}{c}{ Self-Esteem } \\
\cline { 2 - 3 } & R & P Value \\
\hline Sexual self-efficacy & & \\
\hline Mild & 0.49 & -0.06 \\
\hline Moderate & -0.12 & 0.33 \\
\hline Severe & -0.33 & $0.002^{\mathrm{a}}$ \\
\hline Very severe & -0.76 & $0.01^{\mathrm{b}}$ \\
\hline Sexual self-esteem & & \\
\hline Mild & 0.01 & -0.94 \\
\hline Moderate & 0.30 & 0.09 \\
\hline Severe & -0.26 & $0.01^{\mathrm{b}}$ \\
\hline Very severe & -0.23 & 0.52 \\
\hline
\end{tabular}

${ }^{a}$ Correlation is significant at the 0.01 level (2-tailed).

b Correlation is significant at the 0.05 level (2-tailed).

\section{Discussion}

The results of this study showed the status of self-esteem and sexual self-concept in people with physicalmotor disabilities and the relationship between them showed high self-esteem (more than fifteen) in people with physical-motor disabilities. High self-esteem in girls with physical-motor disabilities before intervention was reported in Mojarrad Kahani and Ghanavi's study (5) and Moradi's study (22). In this study, not only self-esteem was not significantly different between men and women, but also their self-esteem had no statistically significant difference in terms of their degree of disability. The lack of gender difference in self-esteem score was also reported in King et al.'s study (23). They also showed the lack of difference between self-esteem scores in disabled and healthy individuals and based on their results suggested that clinical care approach not to be determined assuming that disabled people have lower self-esteem (23).

Investigating the dimensions of sexual self-concept showed that there is no statistical difference in sexual self-esteem scores between both sexes, in other domains (sexual anxiety, sexual self-efficacy, sexual fear and sexual depression) women scored significantly higher than men. Moreover, except for sexual anxiety and sexual selfesteem, there was a statistically significant difference between the mean scores in other domains in the degree of different disabilities, so that the highest mean score of sexual self-efficacy was related to mild degree of disability and the lowest to very severe degree of disability, the highest mean score of sexual fear was related to moderate degree of disability and the lowest to severe disability and the highest mean score of sexual depression was related to very severe degree of disability and the lowest to severe disability. McCabe and Taleporos showed that disability affects sexual self-esteem and sexual depression in women and men, so that a higher sexual depression and lower sexual self-esteem were observed in very severe disabilities. In their study, women reported higher sexual self-esteem and lower sexual depression (24). The difference observed in women and men's self-esteem and sexual depression may be attributed to cultural differences between societies under study, also mentioned in Ziaei et al.(16).

There was a positive relationship between subjects' selfesteem and their sexual anxiety and a negative relationship between their self-esteem and sexual self-efficacy and sexual self-esteem. There was no significant relationship between their self-esteem and sexual fear and sexual depression. Relationships were observed in men and no relationships in women. The positive relationship between self-esteem and sexual anxiety based on the definition of sexual self-concept according to Isfahan youth in Ziaei et al. is justified in that ambiguity of sexual experience, unawareness of genital organ of the opposite sex, lack of knowledge about how to make sexual relation, unknown sexual future in married life and the possibility 
of hurting the sexual partner are known as sexual anxiety. Therefore, in a society like Iran that sexual education has been neglected and young people have no access to it in the course of their development, it has led young people who value themselves and enjoy high self-esteem to gain sexual experience just in the form of marriage. Even in the course of marriage, due to the taboo nature of sexual issues, they are still in uncertainty and ignorance and consult less about their sexual problems and start and continue their married lives with sexual anxiety that stems from lack of knowledge of their sexual lives $(16,25)$. Spencer et al. showed that girls with high self-esteem remain virgin more than low self-esteem (26).

To justify other relationships observed, we can note the inverse relationship between sexual anxiety as a negative sexual self-concept and sexual self-efficacy and sexual self-esteem as a positive self-concept observed in some studies $(14,16,25,27-30)$. Although, there is no obvious, how a reduction or increase of negative sexual self-concept such as sexual anxiety may be influenced by a simultaneous rise or decrease in positive sexual self-concept and how long this effect may last $(12,28,29)$.

No study was found for the inverse relationship between self-esteem and positive sexual self-concept; therefore, there is a need for further studies. Despite of Nosek et al. observed that self-esteem was ominously related to health promoting behaviors (31), Baumeister et al. (32) suggested that self-esteem should be used in a restricted way as one of a group of factors to promote positive outcomes. Nurturing self-esteem will not by itself make people feel better, obey the rules, stay out of misfortune, and respect the rights of others, amongst many other appropriate outcomes. However, it seems to be applicable to enhance people's self-esteem as an incentive for moral behavior and worthy accomplishments (32). Therefore, as Goodson mentioned and our results, questions are remained whether the stress on self-esteem by public health professionals is safe (33).

Lack of self-esteem differences in the disabled people with different degrees of disability and both men and women suggest that disabled people should not be considered as people with low self-esteem. However, to confirm this suggestion, comparative and more extensive studies are needed to investigate disabled and healthy people and also disabled people not covered by the welfare organizations. There is also a need for studies to address psychological, social and environmental factors so that can help disabled people to promote their positive sexual self-concept in the context of marriage and decrease their negative self-concept.

Some of the limitations of this study include the homogeneity of the samples, their being limited to a city, the absence of a comparison group without disability in similar conditions. Furthermore, because the authors did not find a study with similar variables and tools inside and outside Iran, the comparison and justification of the results did not cover a wide range of reasons. One of the strengths of this study is giving importance to the sexual issues of disabled people as one of their essential requirements for a successful sexual life to maintain and continue their married life after marriage.

\section{Acknowledgements}

We would like to thank the manager of Isfahan Welfare Organization and her colleagues. Our special thanks go to the disabled young people anticipated in the study.

\section{Authors' Contributions}

Study concept and design: Tayebe Ziaei, Mehrdad Salehi, Hooman Kharaz Tavakol and Maede Shabani. Analysis and interpretation of data: Tayebe Ziaei, Mehrdad Salehi. Drafting of the manuscript: Tayebe Ziaei. Critical revision of the manuscript for important intellectual content: Tayebe Ziaei, Mehrdad Salehi, Hooman Kharaz Tavakol and Maede Shabani. Statistical analysis: Tayebe ziaei. Acquisition of data: Hooman Kharaz Tavakol and Maede Shabani. Administrative, technical, and material support: Tayebe Ziaei, Mehrdad Salehi, Hooman Kharaz Tavakol and Maede Shabani. Study supervision: Mehrdad Salehi.

\section{Funding/Support}

This study was funded by Isfahan University of Medical Sciences (registered number: 393014).

\section{References}

1. World Health Organisation.. Disabilities and rehabilitation.: WHO 2014. Available from: http://www.who.int/disabilities/world_report/2011/en/.

2. World Health Organization.. World Bank (2011) World report on disability.Malta: WHO;2012.

3. Group TD SMR.. Iran 2011 National Population and Housing Census.Tehran: Technical Report; 2011.

4. World health organization.. Disability prevention and rehabilitation 1981.: WHO.

5. Mojarrad Kahani AH, Ghanavi S. The efficacy of effective communication skills training on the self-esteem of girls with physical - mobility disability.J res rehabil. 2012;1(1):263-71.

6. Maslow AH, Frager R, Fadiman J, McReynolds C, Cox R. Motivation and personality.New York: Harper \& Row; 1970.

7. Baumeister RF, Smart L, Boden JM. Relation of threatened egotism to violence and aggression: the dark side of high self-esteem. Psychol Rev.1996;103(1):5-33.

8. Bushman BJ, Baumeister RF. Threatened egotism, narcissism, self-esteem, and direct and displaced aggression: does self-love or self-hate lead to violence? J Pers Soc Psychol.1998;75(1):219-29.

9. Bushman BJ, Baumeister RF, Thomaes S, Ryu E, Begeer S, West SG. Looking again, and harder, for a link between low self-esteem and aggression. J Pers. 2009;77(2):427-46.

10. Heydari A, Mashak R, Darvishi H. Compare of the Self-Efficacy, Loneliness, Fear of success and Satisfaction in Physically Disabled Students with Normal Students in Ahvaz Islamic Azad University. New Find Psychol. 2009;10(4):7-26.

11. World Health Organization.. Developing Sexual Health Programmes: A Framework for Action.Geneva: WHO; 2010

12. O'Sullivan LF, Meyer-Bahlburg HFL, McKeague IW. The Development of the Sexual Self-Concept Inventory for Early Adolescent Girls. Psychol Women Quart .2006;30(2):139-49.

13. Bong M, Clark RE. Comparison between self-concept and 


\section{Salehi M et al.}

self-efficacy in academic motivation research. Educ Psychol. 1999;34(3):139-53.

14. Andersen BL, Cyranowski JM. Women's sexual self-schema. J Pers Soc Psychol.1994;67(6):1079-100.

15. World Health Organisation.. How to use the ICF.: WHO; 2013.

16. Ziaei T, Merghati KF, Salehi MZF. Sexual Self Concept in Mate Selection: Mixed Methods.Isfahan: Isfahan University of Medical Sciences; 2013.

17. Eysenck SBG, Eysenck HJ, Barrett P. A revised version of the psychoticism scale. Pers Indiv Diffe. 1985;6(1):21-9.

18. Biabangard E. Methods of increasing self-esteem in children and adolesents.: Society guardians and educators publication Republic Islamic of Iran; 1999.

19. Mehrabizadeh honarmand M, Basaknezhad S, Shahni yeilagh M, Shekarkan H, Haghighi J. Assessment simple and multiple relationship of fear of success,self-esteem,perfectionism and fear of negative evaluation with imposter syndrome among post graduate student of Ahwaz University. J Adolescence. 2005.

20. Ziaei T, Khoei EM, Salehi M, Farajzadegan Z. Psychometric properties of the Farsi version of modified Multidimensional Sexual Self-concept Questionnaire. Iran J Nurs Midwifery Res. 2013;18(6):439-45.

21. Plichta Stacey B, Kelvin E. Stastistical methods for health care research. 6 ed; 2013

22. Moradi A. Share of Self-Efficacy. Adv Environ Biol. 2013;7(8):1795-803.

23. King GA, Shultz IZ, Steel K, Gilpin M, Cathers T. Self-evaluation and self-concept of adolescents with physical disabilities. Am J Occup Ther: 1993;47(2):132-40.
24. McCabe MP, Taleporos G. Sexual esteem, sexual satisfaction, and sexual behavior among people with physical disability. Arch Sex Behav. 2003;32(4):359-69.

25. Ziaei T, Ziaei F. The role of sexual self-concept,five factor personality in risky sex behaviour.Hoboken: Wiley-Blackwell; 2013.

26. Spencer JM, Zimet GD, Aalsma MC, Orr DP. Self-esteem as a predictor of initiation of coitus in early adolescents. Pediatrics. 2002;109(4):581-4.

27. Andersen BL, Cyranowski JM, Espindle D. Men's sexual self-schema. J Pers Soc Psychol.1999;76(4):645-61.

28. Hensel DJ, Fortenberry JD, O'Sullivan LF, Orr DP. The developmental association of sexual self-concept with sexual behavior among adolescent women. J Adolesc. 2011;34(4):675-84.

29. O'Sullivan LF, Brooks-Gunn J. The timing of changes in girls' sexual cognitions and behaviors in early adolescence: a prospective, cohort study. J Adolesc Health. 2005;37(3):211-9.

30. Rostosky SS, Dekhtyar O, Cupp PK, Anderman EM. Sexual selfconcept and sexual self-efficacy in adolescents: a possible clue to promoting sexual health? J Sex Res. 2008;45(3):277-86.

31. Nosek MA, Hughes RB, Swedlund N, Taylor HB, Swank P. Self-esteem and women with disabilities. Soc Sci Med. 2003; 56(8):1737-47.

32. Baumeister RF, Campbell JD, Krueger JI, Vohs KD. Does High SelfEsteem Cause Better Performance, Interpersonal Success, Happiness, or Healthier Lifestyles? Psychol Sci Publ. 2003;4(1):1-44.

33. Goodson P, Buhi ER, Dunsmore SC. Self-esteem and adolescent sexual behaviors, attitudes, and intentions: a systematic review.J Adolesc Health. 2006;38(3):310-9. 